Original article

\title{
Attention-deficit/hyperactivity disorder symptoms and perceived mental health discrimination in adults in the general population
}

\author{
Andrew Stickley ${ }^{\mathrm{a}, \mathrm{b}, *}$, Mall Leinsalu ${ }^{\mathrm{b}, \mathrm{c}}$, Vladislav Ruchkin ${ }^{\mathrm{d}, \mathrm{e}}$, Hans $\mathrm{Oh}^{\mathrm{f}}$, Zui Narita $^{\mathrm{g}}$, \\ Ai Koyanagi ${ }^{\text {h,i }}$ \\ a Department of Preventive Intervention for Psychiatric Disorders, National Institute of Mental Health, National Center of Neurology and Psychiatry, 4-1-1 \\ Ogawahigashicho, Kodaira, Tokyo, 1878553, Japan \\ ${ }^{\mathrm{b}}$ The Stockholm Centre for Health and Social Change (SCOHOST), Södertörn University, Huddinge, 141 89, Sweden \\ ${ }^{\mathrm{c}}$ Department of Epidemiology and Biostatistics, National Institute for Health Development, Hiiu 42, 11619 Tallinn, Estonia \\ d Department of Neuroscience, Child and Adolescent Psychiatry Unit, Uppsala University, Uppsala, Sweden \\ e Child Study Centre, Yale University Medical School, New Haven, CT, 06520, USA \\ ${ }^{\mathrm{f}}$ University of Southern California, Suzanne Dworak Peck School of Social Work, 1149 South Hill Street suite 1422, Los Angeles, 90015, CA, United States \\ ${ }^{g}$ Department of Mental Health, Johns Hopkins Bloomberg School of Public Health, 615 N Wolfe St, Baltimore, MD 21205, United States \\ ${ }^{\text {h }}$ Parc Sanitari Sant Joan de Déu, Universitat de Barcelona, Fundació Sant Joan de Déu, Dr Antoni Pujadas, 42, Sant Boi de Llobregat, Barcelona, 08830, Spain \\ i Instituto de Salud Carlos III, Centro de Investigación Biomédica en Red de Salud Mental, CIBERSAM, Monforte de Lemos 3-5 Pabellón 11, Madrid 28029, Spain
}

\section{A R T I C L E I N F O}

\section{Article history:}

Received 29 August 2018

Received in revised form 8 December 2018

Accepted 8 December 2018

Available online 14 January 2019

Keywords:

ADHD

Adult

Discrimination

Epidemiology

\begin{abstract}
A B S T R A C T
Background: The experience of discrimination is common in individuals with mental health problems and has been associated with a range of negative outcomes. As yet, however, there has been an absence of research on this phenomenon in adults with attention-deficit/hyperactivity disorder (ADHD). The current study examined the association between ADHD symptoms and mental health discrimination in the general adult population.

Methods: The analytic sample comprised 7274 individuals aged 18 and above residing in private households in England that were drawn from the Adult Psychiatric Morbidity Survey, 2007. Information on ADHD was obtained with the Adult ADHD Self-Report Scale (ASRS) Screener. A single-item question was used to assess mental health discrimination experienced in the previous 12 months. Logistic regression analysis was used to examine associations.

Results: The prevalence of discrimination increased as ADHD symptoms increased but was especially elevated in those with the most severe ADHD symptoms (ASRS score 18-24). In a multivariable logistic regression analysis that was adjusted for a variety of covariates including common mental disorders, ADHD symptoms (ASRS $\geq 14$ ) were associated with almost 3 times higher odds for experiencing mental health discrimination (odds ratio: $2.81,95 \%$ confidence interval: $1.49-5.31$ ).

Conclusion: ADHD symptoms are associated with higher odds for experiencing mental health discrimination and this association is especially elevated in those with the most severe ADHD symptoms. Interventions to inform the general public about ADHD may be important for reducing the stigma and discrimination associated with this disorder in adults.
\end{abstract}

(c) 2018 Elsevier Masson SAS. All rights reserved.

\section{Introduction}

Discrimination, the behavioural component of stigma [1], has been defined as, "the process by which a member, or members, of a socially defined group is, or are, treated differently (especially unfairly) because of his/her/their membership of that group" [2].

\footnotetext{
* Corresponding author at: Stockholm Centre for Health and Social Change (SCOHOST), Södertörn University, Huddinge 141 89, Sweden.

E-mail address: amstick66@gmail.com (A. Stickley).
}

Although discrimination is experienced by many individuals/ groups in society, it is especially prevalent among people with mental health problems. Individual and cross-country research has shown for example, that as many as $50-90 \%$ of people with mental health problems may experience discrimination [3-6], and that in this population, discrimination can occur across a variety of domains such as in relation to mental and physical health care, as well as from family and friends [6,7].

The high prevalence of discrimination experienced by people with mental health problems is alarming given that it has been associated with a range of negative outcomes including reduced 
social capital and loneliness [8,9], as well as impaired functioning (days out of role) and unemployment [10,11]. There is also some evidence that discrimination may lead to reduced health service use [12,13], and because of this, poorer clinical and personal recovery [14]. Moreover, mental health-related discrimination has also been recently linked to suicidality [15]. Other research has indicated that not only the experience of discrimination but also its anticipation might be associated with negative outcomes among people with mental illness [4]. It is also possible that experienced and anticipated discrimination may lead to greater internalized (mental illness) stigma [16], that has itself been linked to worse psychosocial functioning, increased symptom severity, and poorer treatment adherence in individuals with mental illness [17].

Despite an increasing focus on the association between discrimination and mental health, there are still important gaps in the research with the association remaining unexplored for many disorders. For example, until now, there has been little attention paid to the association between attention-deficit/ hyperactivity disorder (ADHD) and discrimination. To address this omission, the current study will examine the relationship between ADHD symptoms and mental health discrimination in the English adult population. There are several reasons why such a focus is warranted. Not only is ADHD prevalent in the adult population (2.5-5\%) [18-20], but it has also been associated with negative outcomes across a variety of different domains including worse physical and mental health problems/conditions and socioeconomic outcomes [21,22], with even a low (subclinical) number of symptoms being relevant in this context [21,23].

It is also possible that discrimination might be important in relation to this disorder given that several studies have highlighted that adult ADHD is associated with a high degree of stigmatization [24,25]. Indeed, although there has been comparatively little research on stigma among adults with ADHD, an earlier study found that the mere diagnostic label 'ADHD' evoked negative attitudes and a lower desire for work-related/social engagement in college students [26], while other research has suggested that the behaviours associated with the disorder might be important for negative attitudes [26]. In particular, its 'perceived dangerousness' [27] has been suggested as a possible stigmatizing factor, while negative stereotypical behaviours that have been linked to the disorder include laziness and aggression [28]. It is possible that other factors might also contribute to the stigma associated with ADHD. Specifically, a lack of public knowledge about the adult disorder, and the fact that symptom presentation (predominantly inattentive or hyperactive) and severity can vary between individuals, may have also fed into concerns over the reliability of the diagnosis [27], and thus, the stigma attached to it. Nonetheless, regardless, of its specific antecedents, it has been suggested that the stigma related to ADHD might be associated with a number of detrimental outcomes including lower self-esteem and quality of life, as well as greater social isolation [25].

Given the "derision, ridicule, and stigmatization" that has been linked to ADHD [29] and its possible negative consequences, determining the association between ADHD symptomatology and discrimination may have important clinical implications. This study thus had two main aims: (1) to explore whether ADHD symptoms are associated with a higher prevalence of perceived mental health discrimination; (2) to examine if ADHD symptoms are linked to perceived mental health discrimination after adjusting for a number of covariates that might be important for (mental health) discrimination.

\section{Materials and methods}

\subsection{Study sample}

Data were drawn from the Adult Psychiatric Morbidity Survey, 2007 (APMS) $(n=7403)$. This survey was undertaken by the
National Centre for Social Research and the University of Leicester between October 2006 and December 2007. An overview of the survey and its methodology was published shortly after its completion [30]. A nationally representative sample of the adult population in England aged 16 and above residing in private households was obtained using multistage stratified probability sampling. The survey sampling frame was the small user Postcode Address File (PAF) while postcode sectors served as the primary sampling units (PSUs). These sectors were stratified by area and socioeconomic status. Responses were obtained from 7461 of the 13,171 eligible households with one person being recruited from within each household (to give a 57\% survey response rate). The survey obtained information on a range of sociodemographic factors, health behaviours and outcomes and on the respondents' psychopathology. A $£ 5-10$ gift voucher was given to all respondents who took part in the phase one interview as an acknowledgement of thanks for their time. To ensure that the survey was fully representative of its target population (i.e. to correct for survey non-response) sample weights were created. The Royal Free Hospital and Medical School Research Ethics Committee provided ethical approval for the study with all the respondents providing written informed consent for their participation.

\subsection{Measures}

\subsubsection{Perceived mental health discrimination (dependent variable)}

Information on perceived mental health discrimination (and other forms of discrimination) was obtained using computerassisted self-interviews (CASI) as this was considered to be a sensitive topic and previous research has linked the use of CASI to a greater willingness to reveal sensitive information in surveys [31]. Specifically, respondents were asked, "Have you been unfairly treated in the last 12 months, that is since (date), because of your mental health?" with yes and no answer options.

\subsubsection{ADHD symptoms (independent variable)}

Information on ADHD symptoms was collected with the Adult ADHD Self-Report Scale (ASRS) Screener. This 6-item scale, which obtains information on the past 6 month presence of inattention (4 items) and hyperactivity ( 2 items) symptoms, comprises part of a longer 18-item scale that assesses DSM-IV ADHD symptoms in adults. The frequency of symptoms is measured using a 5-point response scale with options running from 'never' - scored 0 , to 'very often' - scored 4 to give an overall score that can range from 0 to 24 , where higher scores indicate increased symptomatology. Following an earlier recommendation, scores were classified in two different ways. Firstly, scores were divided into 4 strata (Stratum I: (score 0-9); II: 10-13; III: 14-17; IV: 18-24) to assess the relation between discrimination and increasing symptomatology. Then the scores were dichotomized with respondents who scored $\geq 14$ considered as having ADHD symptoms [32]. The Cronbach's alpha value for the scale was 0.71 . A previous scale validation study found that the specificity of this scale is high, although it has a lower degree of sensitivity [32].

\subsubsection{Covariates}

Several sociodemographic indicators were included in the analysis: sex, age, ethnicity (white British or other), educational qualification [(degree, non-degree, A-level, General Certificate of Secondary Education (GCSE), other): yes or no], marital status (married/cohabiting or single/divorced/widowed) and equivalized income tertiles (high $\geq £ 29826$, middle $£ 14,057-<£ 29826$, low $<£ 14,057)$. A question which inquired about 18 negative events across the life course (e.g. being expelled from school, bullied, experiencing the death of an immediate family member etc.) was used to assess stressful life events. The number of events was 
summed to give a continuous score that could range from 0-18. Alcohol dependence was examined with two instruments. In the first stage, the Alcohol Use Disorders Identification Test (AUDIT) was used to quantify alcohol consumption [33]. Respondents scoring 10 or above were subsequently assessed for alcohol dependence with the Severity of Alcohol Dependence Questionnaire (SADQ-C) [34] with a score of four and above being used to signify past 6 -month alcohol dependence. Past year drug use was determined by asking respondents if they had consumed one or more of 13 different types of drug in the previous 12 months: cannabis, amphetamines, cocaine, crack, ecstasy, heroin, acid or LSD, magic mushrooms, methadone or physeptone, tranquilizers, amyl nitrate, anabolic steroids, and glues. Those who consumed any of these drugs were coded as positive for drug use. Physical health conditions were assessed by obtaining information on 20 different health conditions diagnosed by a doctor or other health care professional that were present in the previous year (cancer, diabetes, epilepsy, migraine, cataracts/eyesight problems, ear/hearing problems, stroke, heart attack/angina, high blood pressure, bronchitis/ emphysema, asthma, allergies, stomach ulcer or other digestive problems, liver problems, bowel/colon problems, bladder problems/ incontinence, arthritis, bone/back/joint/muscle problems, infectious disease, and skin problems). The total number of conditions was summed for each respondent. Common mental disorders were assessed with the Clinical Interview Schedule Revised (CIS-R) [35]. This measure was used to generate past week ICD-10 diagnoses of depressive episode and anxiety disorders (generalized anxiety disorder, panic disorder, phobia, obsessive-compulsive disorder).

\subsection{Statistical analyses}

The overall sample characteristics were calculated, as were differences in the sample characteristics by any mental health discrimination using Chi-square tests and student's t-tests for categorical and continuous variables, respectively. Next, the prevalence (\%) of mental health discrimination across the four ADHD strata was computed. Finally, a multivariable logistic regression analysis was conducted to assess the association between ADHD symptoms (i.e. score $\geq 14$ based on the ASRS) and mental health discrimination. We were unable to use the four
ADHD strata for this analysis as the small numbers especially among those with high ASRS scores rendered unstable estimates. To determine the degree to which the inclusion of different covariates affects the association between ADHD symptoms and mental health discrimination, a hierarchical analysis was performed with different sets of variables being entered sequentially into the analysis. Five different models were constructed: Model 1 adjusted for sex, age, ethnicity, education (qualification), income and marital status; Model 2 - adjusted for the variables in Model 1 and stressful life events; Model 3 - adjusted for the variables in Model 2 and alcohol dependence and drug use; Model 4 - adjusted for the variables in Model 3 and physical health conditions. Finally, the fully adjusted Model 5 adjusted for the variables in Model 4 while also including common mental disorders.

In all the models, the covariates were categorical variables with the exception of age, number of physical health conditions and stressful life events (continuous variables). As many of the participants had missing data for income (20.7\%), and in an attempt to retain as many cases in the analysis as possible, a missing category was created for this variable and included in the analysis. For other variables, only $\leq 1.5 \%$ of the values were missing. In all analyses, Taylor linearization methods were used so that the sample weighting and the complex study design could be taken into account to enable nationally representative estimates to be produced. The results are presented in the form of odds ratios (ORs) and 95\% confidence intervals (95\% CI). Analyses were performed with Stata version 14.1 (Stata Corp LP, College Station, Texas). The level of statistical significance was set at $\mathrm{P}<0.05$.

\section{Results}

\subsection{Sample characteristics}

Details of the sample characteristics and also stratified by mental health discrimination are presented in Table 1 . The analytic sample included 7274 individuals aged $18-95$. The mean (SD) age of the sample was 47.5 (18.2) years old and $51.6 \%$ of the sample was female. The prevalence of ADHD symptoms and discrimination due to mental health was $5.4 \%$ and $1.1 \%$, respectively. Compared to those who did not experience discrimination due to mental health

Table 1

Sample characteristics (overall and by discrimination due to mental health).

\begin{tabular}{|c|c|c|c|c|c|c|c|c|}
\hline \multirow[b]{2}{*}{ Characteristic } & & \multirow[b]{2}{*}{$\begin{array}{l}\text { Overall } \\
\mathrm{n}\end{array}$} & \multirow[b]{2}{*}{$\%$ or mean $(\mathrm{SD})$} & \multicolumn{4}{|c|}{ Discrimination due to mental health } & \multirow[b]{2}{*}{ P-value } \\
\hline & & & & $\begin{array}{l}\text { No } \\
n\end{array}$ & $\%$ or mean $(\mathrm{SD})$ & $\begin{array}{l}\text { Yes } \\
n\end{array}$ & $\%$ or mean $(\mathrm{SD})$ & \\
\hline \multirow[t]{2}{*}{ Sex } & Male & 3,130 & $48.4 \%$ & 3,049 & $48.6 \%$ & 39 & $44.2 \%$ & 0.467 \\
\hline & Female & 4,144 & $51.6 \%$ & 4,023 & $51.4 \%$ & 52 & $55.8 \%$ & \\
\hline Age (years) & Mean (SD) & & $47.5(18.2)$ & & $47.5(18.1)$ & & $38.6(17.1)$ & $<0.001$ \\
\hline \multirow[t]{2}{*}{ British White } & Yes & 6,396 & $85.3 \%$ & 6,259 & $85.6 \%$ & 79 & $85.9 \%$ & 0.945 \\
\hline & No & 829 & $14.7 \%$ & 790 & $14.4 \%$ & 12 & $14.1 \%$ & \\
\hline \multirow[t]{2}{*}{ Qualification } & No & 2,093 & $24.2 \%$ & 2,026 & $23.9 \%$ & 29 & $30.6 \%$ & 0.182 \\
\hline & Yes & 5,135 & $75.8 \%$ & 5,028 & $76.1 \%$ & 61 & $69.4 \%$ & \\
\hline \multirow[t]{3}{*}{ Income } & High & 1,966 & $36.3 \%$ & 1,947 & $36.7 \%$ & 10 & $15.8 \%$ & $<0.001$ \\
\hline & Middle & 1,922 & $32.8 \%$ & 1,885 & $32.8 \%$ & 21 & $28.3 \%$ & \\
\hline & Low & 1,929 & $30.9 \%$ & 1,864 & $30.5 \%$ & 40 & $55.9 \%$ & \\
\hline \multirow[t]{2}{*}{ Marital status } & Married/cohabiting & 4,130 & $65.2 \%$ & 4,056 & $65.6 \%$ & 23 & $33.8 \%$ & $<0.001$ \\
\hline & Not married/cohabiting & 3,144 & $34.8 \%$ & 3,016 & $34.4 \%$ & 68 & $66.2 \%$ & \\
\hline No. of stressful life events & Mean (SD) & & $3.5(2.5)$ & & $3.5(2.4)$ & & $6.5(3.5)$ & $<0.001$ \\
\hline \multirow[t]{2}{*}{ Alcohol dependence } & No & 6,906 & $94.2 \%$ & 6,740 & $94.4 \%$ & 70 & $70.2 \%$ & $<0.001$ \\
\hline & Yes & 356 & $5.8 \%$ & 332 & $5.6 \%$ & 21 & $29.8 \%$ & \\
\hline \multirow[t]{2}{*}{ Drug use } & No & 6,726 & $91.3 \%$ & 6,583 & $91.4 \%$ & 73 & $76.1 \%$ & $<0.001$ \\
\hline & Yes & 502 & $8.7 \%$ & 479 & $8.6 \%$ & 18 & $23.9 \%$ & \\
\hline Physical health conditions & Mean (SD) & & $1.4(1.5)$ & & $1.4(1.5)$ & & $2.1(1.9)$ & $<0.001$ \\
\hline \multirow[t]{2}{*}{ Common mental disorders } & No & 6,647 & $92.1 \%$ & 6,520 & $92.9 \%$ & 30 & $31.7 \%$ & $<0.001$ \\
\hline & Yes & 627 & $7.9 \%$ & 552 & $7.1 \%$ & 61 & $68.3 \%$ & \\
\hline
\end{tabular}

Abbreviation: SD Standard deviation.

a P-value was estimated by Chi-squared test and Student's $t$-tests for categorical and continuous variables, respectively. 


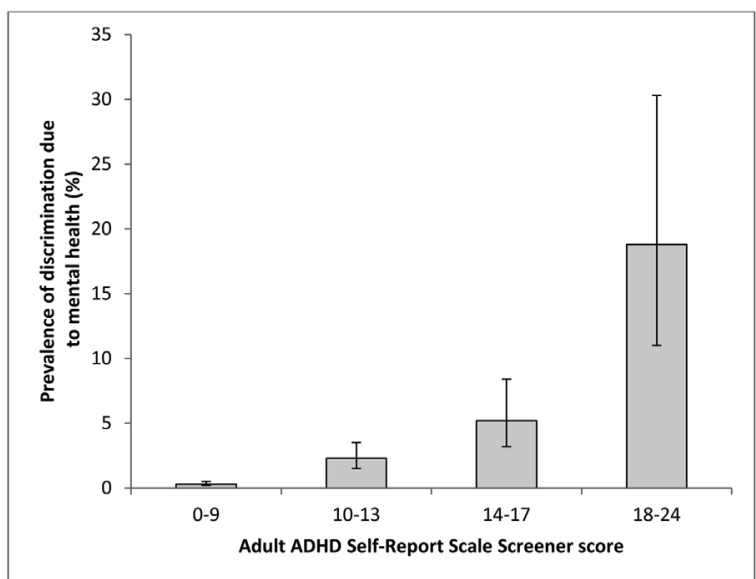

Fig. 1. Prevalence of discrimination due to mental health by severity of ADHD symptoms. Abbreviation: ADHD attention-deficit/hyperactivity disorder. Higher scores on the Adult ADHD Self-Report Scale Screener represent increased ADHD symptoms. Bars denote $95 \%$ confidence intervals.

in the past 12 months, those who did were significantly younger, had a low income, were not married/cohabiting, were more likely to be alcohol dependent and engage in drug use, and have common mental disorders, while they also had greater numbers of stressful life events and physical health conditions.

\subsection{ADHD symptoms and the prevalence of mental health discrimination}

The association between ADHD symptomatology and the prevalence of perceived mental health discrimination is depicted in Fig. 1 using the 4 ADHD strata. For the lowest level of symptoms (Stratum I) there was almost no mental health discrimination reported (0.3\%). As the number of ADHD symptoms increased so did the prevalence of discrimination rising to $2.3 \%$ for those with 10-13 symptoms and to $5.2 \%$ for those with $14-17$ symptoms. However, for those with the most severe symptoms (Stratum IV, 18-24) there was a large and statistically significant difference in the prevalence of perceived mental health discrimination (as signified by the non-overlapping confidence intervals) with $18.8 \%$ (95\% CI:11.0-30.3\%) reporting that they had experienced mental health discrimination in the previous 12 months.

\subsection{ADHD symptoms and mental health discrimination: multivariable analysis}

The results from the multivariable analysis between ADHD symptoms (ASRS $\geq 14$ ) and perceived mental health discrimination are reported in Table 2 . Model 1 that adjusted for sociodemographic variables, showed that ADHD symptoms were associated with almost 10 times higher odds for mental health discrimination (OR: 9.48, 95\% CI: 5.29-16.99). However, the inclusion of stressful life events in Model 2 attenuated the odds greatly (OR: 5.65, 95\% CI: 2.99-10.65). The inclusion of negative health behaviours in Model 3 and physical health conditions in Model 4 also attenuated the odds but to a much smaller degree. The inclusion of common mental disorders in Model 5 also greatly reduced the odds. Indeed, an additional analysis revealed that common mental disorders were much more prevalent in those with more (ASRS $\geq 14$ ) rather than fewer ADHD symptoms (37.5\% vs. 6.2\%). Nonetheless, in the fully adjusted model ADHD symptoms were still associated with almost 3 times higher odds for reporting mental health discrimination (OR: 2.81, 95\% CI: 1.49-5.31).

\section{Discussion}

This study used data from a nationally representative sample of over 7000 household residents in England to examine the association between ADHD symptomatology and perceived mental health discrimination. Increasing ADHD symptoms were associated with a higher prevalence of mental health discrimination, but among those individuals with the highest ADHD symptom scores (ASRS 18-24), the prevalence of mental health discrimination was particularly elevated. Results from a multivariable logistic regression analysis showed that, individuals with ADHD symptoms (ASRS $\geq 14$ ) had almost three times higher odds for experiencing mental health discrimination in the previous year even after adjustment for a variety of different covariates.

Overall, $8.1 \%$ of adults with ADHD symptoms (vs. $0.7 \%$ among those without ADHD symptoms) stated that they had experienced mental health discrimination in the previous year. Assessing this figure is complicated by the fact that previous research on mental health discrimination has focused on populations with specific mental health diagnoses where the prevalence of mental health discrimination is often very high across different life domains [3-6]. However, in an earlier large-scale general population study in the United States, although 33.5\% of the respondents reported

Table 2

Association between ADHD symptoms (ASRS $\geq 14$ ) and discrimination due to mental health estimated by multivariable logistic regression.

\begin{tabular}{|c|c|c|c|c|c|c|c|c|c|c|c|}
\hline \multirow[t]{2}{*}{ Characteristic } & & \multicolumn{2}{|c|}{ Model 1} & \multicolumn{2}{|l|}{ Model 2} & \multicolumn{2}{|l|}{ Model 3} & \multicolumn{2}{|c|}{ Model 4} & \multicolumn{2}{|l|}{ Model 5} \\
\hline & & OR & {$[95 \% \mathrm{CI}]$} & OR & {$[95 \% \mathrm{CI}]$} & OR & {$[95 \% \mathrm{CI}]$} & OR & {$[95 \% \mathrm{CI}]$} & OR & {$[95 \% \mathrm{CI}]$} \\
\hline ADHD symptoms & Yes vs. No & $9.48^{* * *}$ & {$[5.29,16.99]$} & $5.65^{* * *}$ & {$[2.99,10.65]$} & $5.07^{* * *}$ & {$[2.58,9.95]$} & $4.81^{* * *}$ & {$[2.43,9.52]$} & $2.81^{* *}$ & {$[1.49,5.31]$} \\
\hline Sex & Female vs. Male & 1.14 & {$[0.65,2.02]$} & 1.32 & {$[0.75,2.32]$} & 1.46 & {$[0.82,2.58]$} & 1.41 & {$[0.79,2.51]$} & 1.14 & {$[0.67,1.94]$} \\
\hline Age (years) & Per unit increase & $0.97^{* * *}$ & {$[0.96,0.99]$} & $0.97^{* * *}$ & {$[0.95,0.98]$} & $0.97^{* * *}$ & {$[0.95,0.99]$} & $0.96^{* * *}$ & {$[0.94,0.98]$} & $0.96^{* * *}$ & {$[0.95,0.98]$} \\
\hline British White & No vs. Yes & 0.72 & {$[0.34,1.51]$} & 0.80 & {$[0.38,1.65]$} & 0.90 & {$[0.44,1.85]$} & 0.95 & {$[0.46,1.94]$} & 0.72 & {$[0.35,1.51]$} \\
\hline Qualification & Yes vs. No & 0.58 & {$[0.31,1.07]$} & 0.57 & {$[0.32,1.01]$} & $0.54^{*}$ & {$[0.30,0.98]$} & $0.54^{*}$ & {$[0.29,0.99]$} & 0.64 & {$[0.35,1.16]$} \\
\hline \multirow[t]{3}{*}{ Income } & High & 1.00 & {$[1.00,1.00]$} & 1.00 & {$[1.00,1.00]$} & 1.00 & {$[1.00,1.00]$} & 1.00 & {$[1.00,1.00]$} & 1.00 & {$[1.00,1.00]$} \\
\hline & Middle & 1.87 & {$[0.82,4.29]$} & 1.76 & {$[0.76,4.12]$} & 1.79 & {$[0.74,4.33]$} & 1.67 & {$[0.68,4.09]$} & 1.66 & {$[0.69,3.97]$} \\
\hline & Low & $2.65^{*}$ & {$[1.14,6.14]$} & 2.10 & {$[0.86,5.12]$} & 2.35 & {$[0.93,5.94]$} & 2.24 & {$[0.88,5.74]$} & 1.72 & {$[0.71,4.14]$} \\
\hline Marital status & Not married/cohabiting & $2.26^{* *}$ & {$[1.35,3.77]$} & $2.03^{* *}$ & {$[1.19,3.48]$} & $1.89^{*}$ & {$[1.10,3.26]$} & $1.79^{*}$ & {$[1.02,3.16]$} & 1.79 & {$[1.00,3.21]$} \\
\hline Stressful life events & Per unit increase & & & $1.34^{* * *}$ & {$[1.25,1.44]$} & $1.33^{* * *}$ & {$[1.23,1.43]$} & $1.29 * * *$ & {$[1.18,1.41]$} & $1.24^{* * *}$ & {$[1.13,1.35]$} \\
\hline Alcohol dependence & Yes vs. No & & & & & $3.24^{* *}$ & {$[1.60,6.56]$} & $3.39^{* * *}$ & {$[1.66,6.95]$} & $2.69^{* *}$ & {$[1.38,5.24]$} \\
\hline Drug use & Yes vs. No & & & & & 0.77 & {$[0.36,1.67]$} & 0.81 & {$[0.38,1.74]$} & 0.72 & {$[0.32,1.59]$} \\
\hline Chronic physical conditions & Per unit increase & & & & & & & $1.22 *$ & {$[1.04,1.43]$} & 1.09 & {$[0.93,1.27]$} \\
\hline Common mental disorders & Yes vs. No & & & & & & & & & $10.83^{* * *}$ & {$[5.66,20.73]$} \\
\hline
\end{tabular}

Abbreviation: ADHD attention-deficit/hyperactivity disorder.

Data are odds ratios (OR) with $95 \%$ confidence intervals (CI).

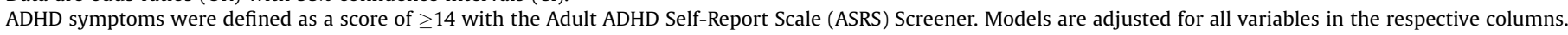
${ }^{*} p<0.05,{ }^{* *} p<0.01$, *** $p<0.001$. 
any lifetime discrimination, only 3.6\% stated that physical/mental disability was the reason for their perceived (lifetime/day-to-day) discrimination [36]. Given this, our results suggest that mental health discrimination may be significantly elevated in those with ADHD symptoms and especially among individuals with the most severe symptoms.

It is uncertain what exactly underlies the higher odds for mental health discrimination among those with ADHD symptoms. Even after adjusting for factors that are common in individuals with ADHD symptoms [37,38], and that have been linked to mental health discrimination in groups with other mental health disorders, ADHD symptoms continued to be associated with significantly increased odds for past year mental health discrimination. This uncertainty is compounded by the fact that almost no individuals in the sample were taking ADHD medication (Ritalin or Straterra) [30], so it is feasible to assume that the vast majority of individuals in the ADHD symptom category either did not have an ADHD diagnosis or did not know that they might have ADHD, a supposition which is supported by findings from the most recent version (2014) of the Adult Psychiatric Morbidity Survey where very few adults who screened positive for ADHD either believed they had the disorder (3.7\%) or had an ADHD diagnosis by a professional (2.3\%) [39]. The question then becomes why would they report experiencing mental health-related discrimination?

In terms of perceived/experienced discrimination more generally, it can be hypothesized that those with the highest level of ADHD symptoms encounter this more often because they exhibit the most problematic behaviours which are met with a more negative response. The main symptoms of ADHD - inattention, hyperactivity and impulsivity [18] have all been associated with a range of negative outcomes for adults across different domains including in the home and at work. For example, the reduced occupational functioning that has been observed in adults with ADHD [40] might explain why ADHD carries an increased risk for unemployment [41]. Moreover, other research has described how individuals with ADHD may suffer from a range of deficits such as indecisiveness, procrastination, poor time management, motivational difficulties as well as being easily bored, which not only create difficulties in their own everyday lives [25] but might also affect the people around them and provoke a negative response. This might explain why there is some evidence that individuals with ADHD not only have greater interpersonal difficulties but may also perceive more negative behaviours being directed against them (e.g. receiving more criticism of their behaviour and being taken advantage of) [42], which for some, might fuel feelings of being discriminated against.

It can only be speculated why many individuals, most probably without a diagnosis of ADHD, might perceive some of the life course difficulties they encounter as being examples of mental health discrimination. Given the reduction in the odds ratio when common mental disorders were included in the analysis and the fact that common mental disorders were much more prevalent among those individuals with ADHD symptoms, it is possible that some individuals may have had a comorbid/differential diagnosis or other undiagnosed disorders and it is that which they were associating with mental health discrimination. Nonetheless, by itself, this may not fully explain the association we observed, as even after controlling for common mental disorders in the analysis, the odds ratio for discrimination was still significantly elevated in those with ADHD symptoms. This highlights the need for future research to determine the specific factors that are associated with perceived mental health discrimination in adults with ADHD symptoms.

This study has several limitations that should be discussed. First, information on mental health discrimination was collected with a single dichotomous item. Hence, we had no details of the type/nature of the discrimination, who was involved, whether there was more than one episode occurring across different domains, how severe it was, or what were the consequences of the discrimination. This information would have helped us to better understand the association between ADHD symptoms and mental health discrimination and should thus be collected in future studies on this topic. Second, as the survey response rate was only $57 \%$ [30] it is possible that those with ADHD symptoms and/or more experience of mental health discrimination might have been less likely to participate, thus potentially affecting the results. An earlier study of discrimination among people using mental health services in England reported very low response rates for example [6]. Third, given the potentially sensitive nature of the topic of mental health discrimination, it is possible that this phenomenon may have been underreported, although allowing the respondents to self-complete this question may have reduced the risk of social desirability bias. Fourth, the dataset we used at the time of writing this paper was the most up-to-date publicly available version of the Adult Psychiatric Morbidity Survey. Nonetheless, it was still a decade old. Further research is thus needed with more recent data to see if/how the associations we observed in this study have changed across time. Fifth, as the number of individuals in the most severe ADHD symptom category was small, there was a wide confidence interval for the discrimination point estimate. Sixth, given that we focused on ADHD symptoms, rather than diagnosed ADHD, we cannot discount the possibility that we may have been measuring symptoms of other disorders which can sometimes overlap with ADHD symptoms such as those related to bipolar disorder, major depressive disorder, generalized anxiety disorder, and substance use disorders [43] although we were able to control for common mental disorders in the analysis.

In conclusion, this study has shown that individuals with ADHD symptoms have a significantly increased risk of experiencing mental health discrimination. This is an important finding given that mental health discrimination has been associated with detrimental consequences in individuals with mental health disorders and therefore might also be a factor in the negative outcomes that have been noted in adults with ADHD/ADHD symptomatology. As ADHD continues to be underdiagnosed and untreated in adults [28], the results of this study highlight the importance of identifying and treating these individuals and suggest that interventions to inform the public about ADHD may be important for reducing the stigma and discrimination associated with this condition.

\section{Conflicts of interest}

None.

\section{Acknowledgements}

AK's work was supported by the Miguel Servet contract financed by the CP13 / 00150 project, integrated into the National $\mathrm{R}+\mathrm{D}+\mathrm{I}$ and funded by the ISCIII - General Branch Evaluation and Promotion of Health Research - and the European Regional Development Fund (ERDF-FEDER). These organizations had no role in the study design, collection, analysis and interpretation; in the writing of the manuscript; and in the decision to submit the paper for publication.

\section{References}

[1] Corker EA, Beldie A, Brain C, Jakovljevic M, Jarema M, Karamustafalioglu O, et al. Experience of stigma and discrimination reported by people experiencing the first episode of schizophrenia and those with a first episode of depression: the FEDORA project. Int J Soc Psychiatry 2015;61:438-45. 
[2] Krieger N. A glossary for social epidemiology. J Epidemiol Community Health 2001;55:693-700.

[3] Corrigan P, Thompson V, Lambert D, Sangster Y, Noel JG, Campbell J. Perceptions of discrimination among persons with serious mental illness. Psychiatr Serv 2003;54:1105-10.

[4] Lasalvia A, Zoppei S, Van Bortel T, Bonetto C, Cristofalo D, et al. Global pattern of experienced and anticipated discrimination reported by people with major depressive disorder: a cross-sectional survey. Lancet 2013;381:55-62.

[5] Ye J, Chen TF, Paul D, McCahon R, Shankar S, Rosen A, et al. Stigma and discrimination experienced by people living with severe and persistent mental illness in assertive community treatment settings. Int J Soc Psychiatry 2016;62:532-41.

[6] Corker E, Hamilton S, Henderson C, Weeks C, Pinfold V, Rose D, et al. Experiences of discrimination among people using mental health services in England 2008-2011. Br J Psychiatry 2013;202:s58-63.

[7] Hamilton S, Pinfold V, Cotney J, Couperthwaite L, Matthews J, Barret K, et al. Qualitative analysis of mental health service users' reported experiences of discrimination. Acta Psychiatr Scand 2016;134(Suppl 446):14-22.

[8] Webber M, Corker E, Hamilton S, Weeks C, Pinfold V, Rose D, et al. Discrimination against people with severe mental illness and their access to social capital: findings from the Viewpoint survey. Epidemiol Psychiatr Sci 2014;23:155-65.

[9] Świtaj P, Grygiel P, Anczewska M, Wciórka J. Experiences of discrimination and the feelings of loneliness in people with psychotic disorders: the mediating effects of self-esteem and support seeking. Compr Psychiatry 2015;59:73-9.

[10] Breslau J, Wong EC, Burnam MA, Cefalu M, Roth EA, Collins RL. Associations of perceived discrimination with impaired functioning in a population sample with psychological distress. Psychiatry 2018;81:130-40.

[11] Brouwers EP, Mathijssen J, Van Bortel T, Knifton L, Wahlbeck K, et al. Discrimination in the workplace, reported by people with major depressive disorder: a cross-sectional study in 35 countries. BMJ Open 2016;6:e009961.

[12] Osumili B, Henderson C, Corker E, Hamilton S, Pinfold V, Thornicroft G, et al. The economic costs of mental health-related discrimination. Acta Psychiatr Scand 2016;134(Suppl. 446):34-44.

[13] Clement S, Williams P, Farrelly S, Hatch SL, Schauman O, Jeffery D, et al. Mental health-related discrimination as a predictor of low engagement with mental health services. Psychiatr Serv 2015;66:171-6.

[14] Mak WW, Chan RC, Wong SY, Lau JT, Tang WK, Tang AK, et al. A cross-diagnostic investigation of the differential impact of discrimination on clinical and personal recovery. Psychiatr Serv 2017;68:159-66.

[15] Farrelly S, Jeffery D, Rüsch N, Williams P, Thornicroft G, Clement S. The link between mental health-related discrimination and suicidality: service user perspectives. Psychol Med 2015;45:2013-22.

[16] Quinn DM, Williams MK, Weisz BM. From discrimination to internalized mental illness stigma: the mediating roles of anticipated discrimination and anticipated stigma. Psychiatr Rehabil J 2015;38:103-8.

[17] Livingston JD, Boyd JE. Correlates and consequences of internalized stigma for people living with mental illness: a systematic review and meta-analysis. Soc Sci Med 2010;71:2150-61.

[18] American Psychiatric Association. Diagnostic and statistical manual of mental disorders. 5th edn. Arlington, VA: APA; 2013.

[19] Fayyad J, De Graaf R, Kessler R, Alonso J, Angermeyer M, et al. Cross-national prevalence and correlates of adult attention-deficit hyperactivity disorder. Br J Psychiatry 2007;190:402-9.

[20] Willcutt EG. The prevalence of DSM-IV attention-deficit/hyperactivity disorder: a meta-analytic review. Neurotherapeutics 2012;9:490-9.

[21] Das D, Cherbuin N, Butterworth P, Anstey KJ, Easteal S. A population-based study of attention deficit/hyperactivity disorder symptoms and associated impairment in middle-aged adults. PLoS One 2012;7:e31500.

[22] Agnew-Blais JC, Polanczyk GV, Danese A, Wertz J, Moffitt TE, et al. Young adult mental health and functional outcomes among individuals with remitted, persistent and late-onset ADHD. Br J Psychiatry 2018;213:526-34.

[23] Vogel SWN, Ten Have M, Bijlenga D, de Graaf R, Beekman ATF, et al. Distribution of ADHD symptoms, and associated comorbidity, exposure to risk factors and disability: results from a general population study. Psychiatry Res 2018;267:256-65.

[24] Lebowitz MS. Stigmatization of ADHD: a developmental review. J Atten Disord 2016:20:199-205.

[25] Holthe MEG, Langvik E. The strives, struggles and successes of women diagnosed with ADHD as adults. Sage Open 2017;7:1-12.

[26] Canu WH, Newman ML, Morrow TL, Pope DL. Social appraisal of adult ADHD: stigma and influences of the beholder's Big five personality traits. J Atten Disord 2008;11:700-10.

[27] Mueller AK, Fuermaier AB, Koerts J, Tucha L. Stigma in attention deficit hyperactivity disorder. Atten Defic Hyperact Disord 2012;4:101-14.

[28] Kooij SJ, Bejerot S, Blackwell A, Caci H, Casas-Brugué M, et al. European consensus statement on diagnosis and treatment of adult ADHD: the European Network Adult ADHD. BMC Psychiatry 2010;10:67.

[29] Hinshaw SP. Attention deficit hyperactivity disorder (ADHD): controversy, developmental mechanisms, and multiple levels of analysis. Annu Rev Clin Psychol 2018;14:291-316.

[30] McManus S, Meltzer H, Brugha T, Bebbington P, Jenkins R. Adult psychiatric morbidity in England, 2007: results of a household survey. London: National Centre for Social Research; 2009.

[31] Tourangeau R, Smith TW. Asking sensitive questions: the impact of data collection mode, question format, and question context. Public Opin Q 1996;60:275-304.

[32] Kessler RC, Adler LA, Gruber MJ, Sarawate CA, Spencer T, Van Brunt DL. Validity of the World Health Organization Adult ADHD Self-Report Scale (ASRS) Screener in a representative sample of health plan members. Int J Methods Psychiatr Res 2007; 16:52-65.

[33] Saunders JB, Aasland OG, Babor TF, de la Fuente JR, Grant M. Development of the Alcohol Use Disorders Identification Test (AUDIT): WHO collaborative project on early detection of persons with harmful alcohol consumption-II. Addiction 1993;88:791-804.

[34] Stockwell T, Sitharthan T, McGrath D, Lang E. The measurement of alcohol dependence and impaired control in community samples. Addiction 1994;89:167-74.

[35] Lewis G, Pelosi AJ, Araya R, Dunn G. Measuring psychiatric disorder in the community: a standardized assessment for use by lay interviewers. Psychol Med 1992;22:465-86.

[36] Kessler RC, Mickelson KD, Williams DR. The prevalence, distribution, and mental health correlates of perceived discrimination in the United States. J Health Soc Behav 1999;40:208-30.

[37] Friedrichs B, Igl W, Larsson H, Larsson JO. Coexisting psychiatric problems and stressful life events in adults with symptoms of ADHD-a large Swedish population-based study of twins. J Atten Disord 2012;16:13-22.

[38] Stickley A, Koyanagi A, Takahashi H, Ruchkin V, Inoue Y, Kamio Y. Attentiondeficit/hyperactivity disorder and physical multimorbidity: a populationbased study. Eur Psychiatry 2017;45:227-34.

[39] Brugha T, Asherson P, Strydom A, Morgan Z, Christie S. Attention-deficit/ hyperactivity disorder. In: McManus S, Bebbington P, Jenkins R, Brugha T, editors. Mental health and wellbeing in England: adult psychiatric morbidity survey 2014. Leeds: NHS Digital; 2016. p. 199-219.

[40] Kirino E, Imagawa H, Goto T, Montgomery W. Sociodemographics, comorbidities, healthcare utilization and work productivity in Japanese patients with adult ADHD. PLoS One 2015; 10:e0132233.

[41] de Zwaan M, Gruss B, Müller A, Graap H, Martin A, et al. The estimated prevalence and correlates of adult ADHD in a German community sample. Eur Arch Psychiatry Clin Neurosci 2012;262:79-86.

[42] Able SL, Johnston JA, Adler LA, Swindle RW. Functional and psychosocial impairment in adults with undiagnosed ADHD. Psychol Med 2007;37:97-107.

[43] Katzman MA, Bilkey TS, Chokka PR, Fallu A, Klassen LJ. Adult ADHD and comorbid disorders: clinical implications of a dimensional approach. BMC Psychiatry 2017;302, doi:http://dx.doi.org/10.1186/s12888-017-1463-3. 